\title{
Design of an Emergency Footbridge
}

\author{
S.Rihal ${ }^{1}$, M.W.Kamerling ${ }^{2}$ \\ ${ }^{r}$ professor emiritus College of Architecture and Environmental Design, \\ California Polytechnic State University, San Luis Obispo, California, \\ USA, \\ ${ }^{2}$ Ass. professor Department of Architectural Engineering, Faculty of \\ Architecture, Technical University of Delft, Delft, The Netherlands.
}

\begin{abstract}
This paper will describe the design of a temporary emergency floating footbridge, to be made when the infrastructure is destroyed by a flood, hurricane, tsunami or any other disaster. The bridge is made of identical floating modules. The modules are composed of prefabricated elements: two trusses, a pontoon and the footpath. The height of the trusses is integrated with the handrail. The sides of the pontoons are inclined to stack these elements during transport. The modules are assembled at the site. A completed module is fastened to the other modules of the bridge. The completed bridge is floated into position. Thanks to the combination of trusses and pontoons, the deformations under expected loadings are reduced considerately. Structurally the pontoons can be considered as flexible supports for the trussed bridge, spanning between the river banks.
\end{abstract}

Keywords: Temporary emergency footbridge, floating, transportable

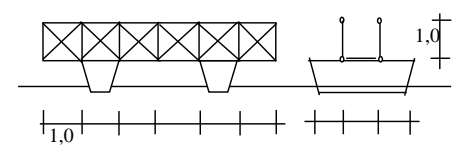

Figure 1: $\quad$ Two modules of the footbridge 


\section{Introduction}

Every year severe floods, storms, hurricanes and other disasters cause immense suffering for millions of people around the globe. Generally helping the victims quickly is difficult, especially in case the infrastructure is destroyed and transport by road is nearly impossible. Rivers and canals, swollen by heavy rainfall, can be dangerous to cross. Small temporary foot bridges constructed at the site will be most helpful for people to cross rivers and canals to get drinking water, food, medical assistance and shelter. These bridges have to facilitate the passage of people, just after the disaster for some months until a more permanent bridge is constructed. Next the temporary bridges will be disassembled and pulled down. After a disaster people need materials to repair their houses. Building materials will be rare, thus it will be helpfully if the parts of the bridges can be reused for houses, hospitals, shops, offices and so on.

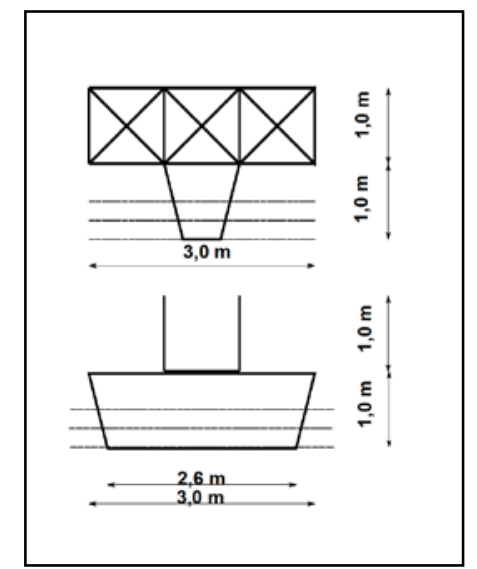

Figure 2: $\quad$ A module of the bridge.

Probably most roads will be damaged and heavy equipment, trucks and cranes will not be available at the site. By preference the elements of the bridge has to be light and easily to transport. Further the bridge must be constructed without help of heavy equipment. Most bridges are supported with piers resting on piles driven deeply into the ground. For the emergency bridge there will be not any equipment to drive piles in the days just after the disaster. Floating bridges do not need substantial supports, the pontoons are very light and can be transported easily. Further the pontoons will facilitate the construction much. Of course a floating bridge has some drawbacks. The deformation of the pontoons can be substantial, especially if a load acts eccentrically at the bridge. Actually the designed bridge is a trussed bridge. The upper chords of the trusses are integrated with the handrails at both side of the bridge to support the people to cross the river safely. The two trusses at the sides of the footpath, spanning from 
bank to bank, are quite stiff and significantly reduce the deformations. In use the pontoons can be considered as flexible supports which help to increase the maximal span of the bridge.

\section{Construction}

The modules are constructed at the site by assembling prefabricated parts with a length of 3,0 $\mathrm{m}$ at maximum, so the elements can be transported easily with a small car. A module is composed of two trusses, a floating box and a footpath. Every module is supported by one floating box, connecting two modules gives a stable structure supported by two pontoons, just as a catamaran. Due to the length of the pontoons the bridge is stable and can stand lateral forces. The sides of the boxes are inclined so the boxes can be stacked, thus the volume to be stored and to be transported is minimal. The elements are made of aluminium to reduce the weight and to facilitate transport and construction. The parts can be lifted by two persons only.

The completed bridge is floated into position with help of pulleys and ropes till both sides are connected. The ropes, fastened to trees, rocks and other stiff objects on the riverbanks, will prevent the bridge to float away down the river. At the banks the bridge can be supported vertically and horizontally. The trusses span from bank to bank, nevertheless the pontoons will support the bridge too, thanks to these flexible supports the stresses and deformations will be reduced considerately.

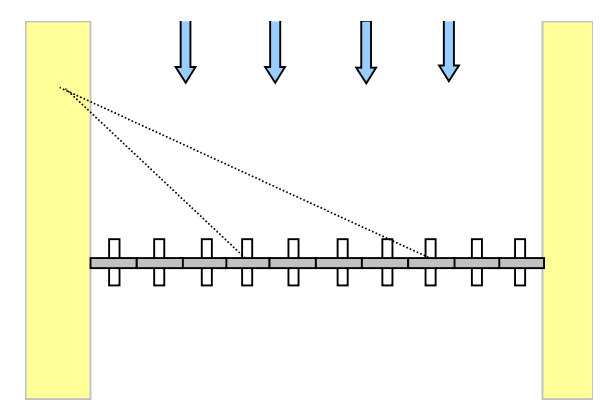

Figure 3: Construction.

\section{The elements of the structure}

The structure is composed of aluminum AL EN AW 6082 T6, with an ultimate stress of $R_{p 0,2}=250 \mathrm{MPa}$. Table 1 shows the sections of the profiles. 
Table 1: $\quad$ Dimensions

\begin{tabular}{llcc}
\hline element & & section & area $\left[\mathrm{mm}^{2}\right]$ \\
\hline truss & chord & $50 * 50 * 2$ & 384 \\
truss & diagonal web bar & $40 * 40 * 2$ & 304 \\
footpath & beam & $50 * 50 * 2$ & 384 \\
footpath & corrugated plate & $20 *(25+20+25) * 1$ & 1400 \\
pontoon & plate & $1000 * 2$ & 2000 \\
& beams & $20 * 20 * 2$ & 144 \\
\hline
\end{tabular}

The loads acting at the structure are as follows:

Permanent loads: dead weight, truss and footpath: dead weight pontoon:

$\mathrm{q}=0,2 \mathrm{kN} / \mathrm{m}$

phase during construction:

$\mathrm{F}=0,5 \mathrm{kN}$

Live loads: $\quad$ phase during

$\mathrm{q}=1,0 \mathrm{kN} / \mathrm{m}, \mathrm{e}=0,5 \mathrm{~m}$

$\mathrm{p}=2,0 \mathrm{kN} / \mathrm{m}^{2}$

\section{Design of the pontoons}

The sinking depth of the pontoon follows from the vertical equilibrium. The uplift of the pontoon must be larger than the vertical load. According to Archimedes the uplift is equal to the weight of the water of the volume of the pontoon below the water level. The mass of water is equal to $1000 \mathrm{~kg} / \mathrm{m}^{3}$. For a load $\mathrm{dF}$ acting at the floating bridge and a pontoon with volume $\mathrm{b}^{*} \mathrm{~h}^{*} l \mathrm{~m}^{3}$ the deformation $\Delta$ is according to Timoshenko et al [1] equal to:

$$
\Delta=\mathrm{dF} / \mathrm{C}_{\mathrm{d}}[\mathrm{m}]
$$

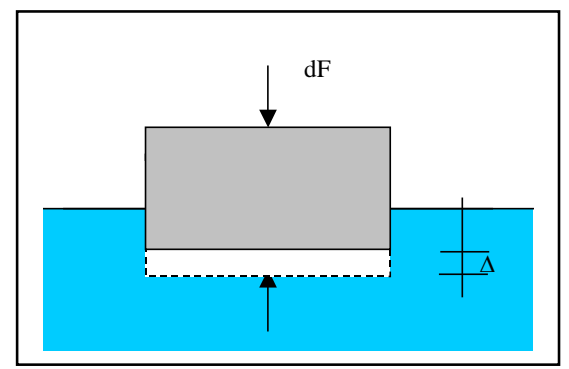

Figure 4: $\quad$ Deformation $\Delta$. due to load $\mathrm{dF}$

The resiliency ratio $C_{d}$ of the pontoon with area $A_{d}$ concerning a vertical load $d F$ is equal to:

$$
\mathrm{C}_{\mathrm{d}}=10 * \mathrm{~A}_{\mathrm{d}}[\mathrm{kN} / \mathrm{m}]
$$




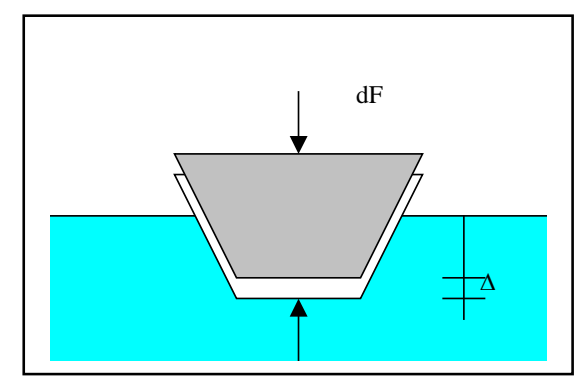

Figure 5: $\quad$ Deformation $\Delta$ due to a load $\mathrm{dF}$

The sides of the pontoon are inclined and parallelograms. The surface of the top and bottom are respectively $1,0 * 3,0 \mathrm{~m}^{2}$ and $0,6 * 2,6 \mathrm{~m}^{2}$. At the water level the area of the pontoon is for a depth d equal to:

$$
A_{d}=(0,6+2 * d * 0,2 / 1,0) *(2,6+2 * d * 0,2 / 1,0) \quad\left[m^{2}\right]
$$

The sinking of the pontoon is calculated with expression (1), (2) and (3). For the self weight of the module, $\mathrm{G}=1,1 \mathrm{kN}$, the depth is equal to $\mathrm{d}=0,07 \mathrm{~m}$. Adding a live load of $\mathrm{F}=3,0 \mathrm{kN}$ increases the depth to $\mathrm{d}=0,22 \mathrm{~m}$. For this depth the area of the pontoon is equal to $\mathrm{A}=1,85 \mathrm{~m}^{2}$ and the resiliency of the flexible support is equal to $C_{d}=18,5 \mathrm{kN} / \mathrm{m}$. For a increasing load the stiffness will increase slightly. For a depth of $d=0,5 \mathrm{~m}$, the resiliency is equal to $\mathrm{C}_{\mathrm{d}}=22,4$ $\mathrm{kN} / \mathrm{m}$.

Table 2: $\quad$ Resiliency $\mathrm{C}_{\mathrm{d}}$ pontoon

\begin{tabular}{lll}
\hline Load & depth & resiliency $\mathrm{C}_{\mathrm{d}}$ \\
\hline $\mathrm{F}=4,3 \mathrm{kN}$ & $\mathrm{d}=0,25 \mathrm{~m}$ & $\mathrm{C}_{\mathrm{d}}=18,9 \mathrm{kN} / \mathrm{m}$ \\
$\mathrm{F}=9,5 \mathrm{kN}$ & $\mathrm{d}=0,50 \mathrm{~m}$ & $\mathrm{C}_{\mathrm{d}}=22,4 \mathrm{kN} / \mathrm{m}$ \\
$\mathrm{F}=15,6 \mathrm{kN}$ & $\mathrm{d}=0,75 \mathrm{~m}$ & $\mathrm{C}_{\mathrm{d}}=26,1 \mathrm{kN} / \mathrm{m}$ \\
$\mathrm{F}=22,8 \mathrm{kN}$ & $\mathrm{d}=1,00 \mathrm{~m}$ & $\mathrm{C}_{\mathrm{d}}=30,0 \mathrm{kN} / \mathrm{m}$ \\
\hline
\end{tabular}

Due to a bending moment the pontoon will rotate. The dimensions of the pontoon must be so large that the structure is stable and does not rotate excessively. The maximal deformation $\Delta$ due to a moment $\mathrm{M}$ follows from:

$$
\Delta=\frac{\mathrm{M} * 1 / 2 * l}{\mathrm{C}_{\phi}}[\mathrm{m}]
$$

For a pontoon with an area $\mathrm{A}=\mathrm{b} * l \mathrm{~m}^{2}$ the rotational resiliency $\mathrm{C}_{\phi}$ of the pontoon is equal to:

$$
\mathrm{C}_{\phi}=10 * \mathrm{~b} . l^{3} / 12 \quad[\mathrm{kNm} / \mathrm{rad}]
$$




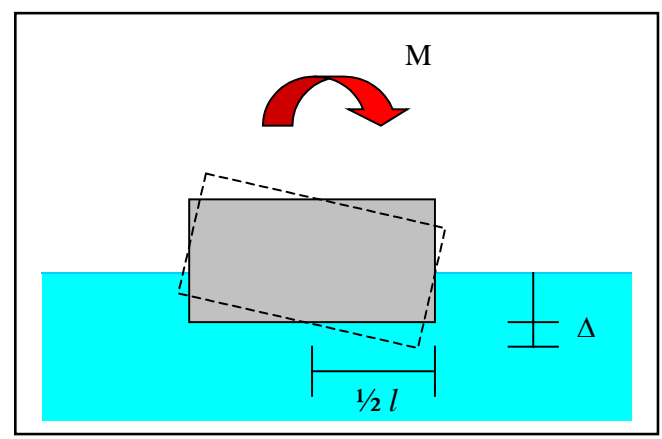

Figure 6: Rotation

For a depth of $\mathrm{d}=0,22 \mathrm{~m}$ the area of the pontoon is equal to $\mathrm{A}=1,85 \mathrm{~m}^{2}$. Then the rotational resiliency $\mathrm{C}_{\phi}$ of the pontoon is according to expression (5) equal to:

$$
\mathrm{C}_{\phi}=10 * 0,69 * 2,69^{3} / 12=11,2 \mathrm{kNm} / \mathrm{rad} \text { (6) }
$$

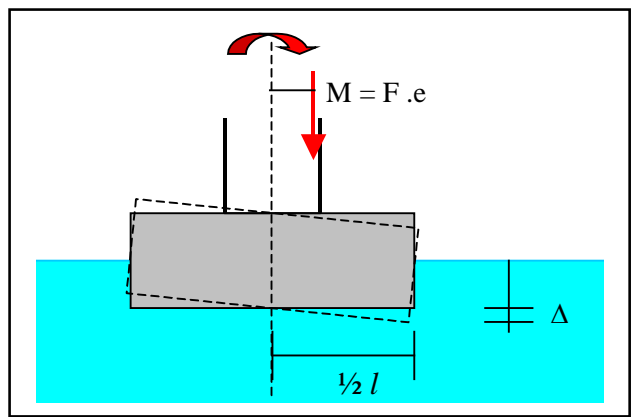

Figure 7: $\quad$ Rotation due to eccentric load

The eccentricity of the live load is $0,5 \mathrm{~m}$ at maximum. For this eccentricity and a variable load $\mathrm{F}=3,0 \mathrm{kN}$ the moment is equal to $3,0 * 0,5=1,5 \mathrm{kNm}$. Due to this moment the deformation $\Delta$ is according to expression (4) equal to:

$$
\Delta=\frac{1,5 * 1 / 2 * 2,69}{11,2}=0,18 \mathrm{~m}
$$

Thus the maximum depth of the pontoon due to the eccentric vertical load and the moment is equal to:

$$
\mathrm{d}_{\max }=0,22+0,18 \mathrm{~m}=0,4 \mathrm{~m} .
$$

A floating object is stable if the meta-centre is above the centre of gravity. The position of the meta-centre with respect to the centre of buoyancy is calculated with:

$$
\mathrm{Mc}=\left({ }^{1} /{ }_{12} \mathrm{~b} \cdot \mathrm{h}^{3}\right) / \mathrm{V}
$$




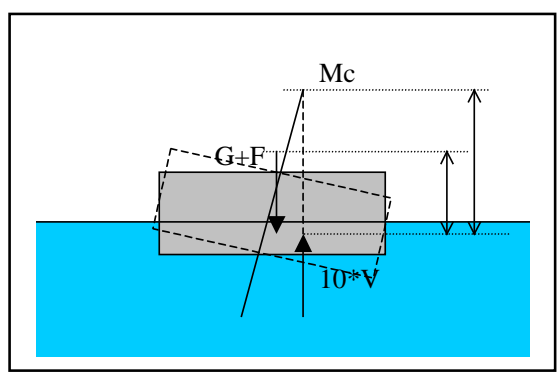

Figure 8: Stability.

$\mathrm{V}$ is the volume of the pontoon under the waterline. For $\mathrm{b}=0,69 \mathrm{~m}, \mathrm{~h}=2,69 \mathrm{~m}$ and $\mathrm{d}=0,22 \mathrm{~m}$ the volume is equal to $\mathrm{V}=0,375 \mathrm{~m}^{3}$ and the distance between the meta-centre and the centre of buoyancy is $\mathrm{Mc}=2,97 \mathrm{~m}$. The load acts at a distance of 0,99 $\mathrm{m}$ above the centre of buoyancy, so the structure is stable.

The skin of the pontoon is subjected to hydrostatically applied load. The skin is supported by stiffeners at a centre to centre distance of $\mathrm{a}=0,5 \mathrm{~m}$. The plate can be considered as a rectangular plate with three sides built in and at the top simple supported. According to Timoshenko et al [2] the maximum bending moment is equal to $\mathrm{M}=0,0364 * \mathrm{q} \cdot \mathrm{a}^{2} \mathrm{kNm}$. For a hydrostatic load $\mathrm{q}=7,5 \mathrm{kN} / \mathrm{m}^{2}$ and $\mathrm{a}=0,5$ the maximum bending moment is equal to $\mathrm{M}=0,069 \mathrm{kNm}$. For this moment the stress is equal to $\sigma=0,069 * 10^{6} / 666=104 \mathrm{MPa}$.

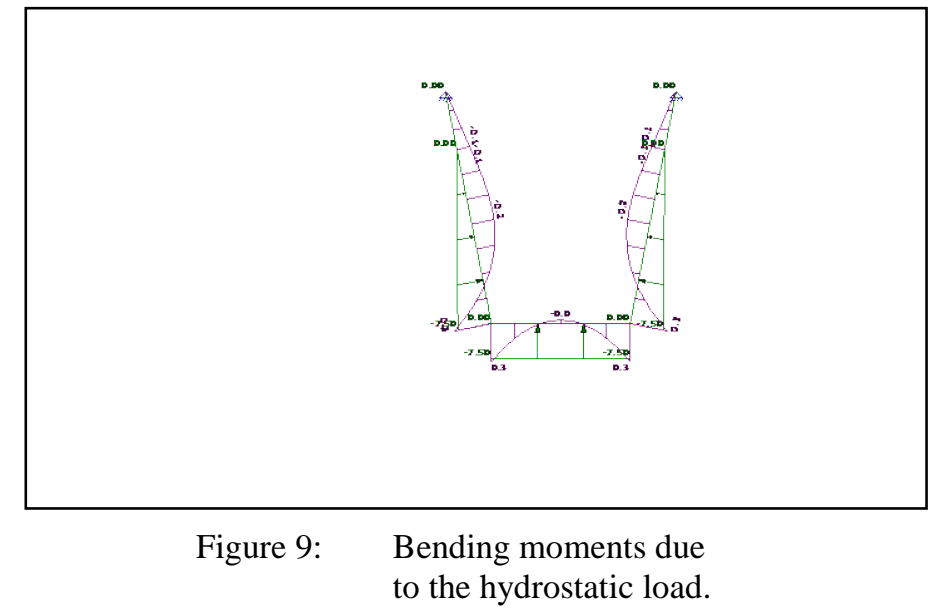

The stiffeners of the pontoon are rectangular tubes, with a section $20 * 20 * 2$ and a centre to centre distance of $500 \mathrm{~mm}$. These elements are subjected to the hydrostatic load of $\mathrm{p}=\mathrm{p}=7,5 \mathrm{kN} / \mathrm{m}^{2}$ at maximum. The bending moments are calculated with a finite element program. For a hydrostatic load $\mathrm{p}=7,5 \mathrm{kN} / \mathrm{m}^{2}$ 
the maximum bending moment is equal to $\mathrm{M}=0,155 \mathrm{kNm}$. For this moment the stress is equal to $\sigma=0,155 * 10^{6} / 787=197 \mathrm{MPa}$.

\section{Design of the trusses}

During the construction the floating bridge is supported by the pontoons. The pontoons, supporting the bridge, can be considered as flexible supports. For one truss the resiliency of a flexible support is equal to $C_{d}=1 / 4 * 1,69=4,2 \mathrm{kN} / \mathrm{m}$. With a finite element program the deformations and stresses are calculated for the construction phase and final phase for varying load conditions for a bridge composed of 21 modules.

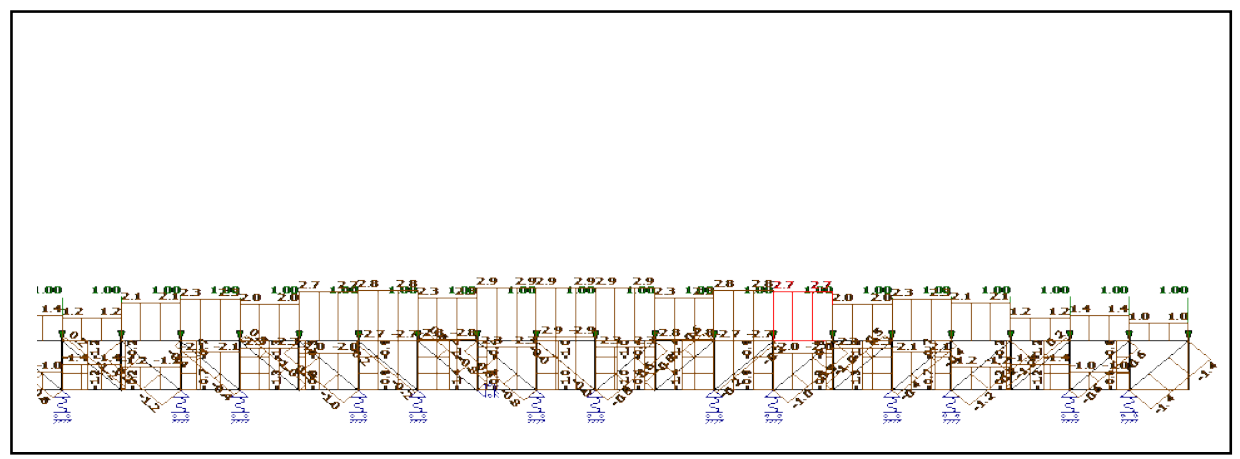

Figure 10: $\quad$ Symmetrical live load, forces.

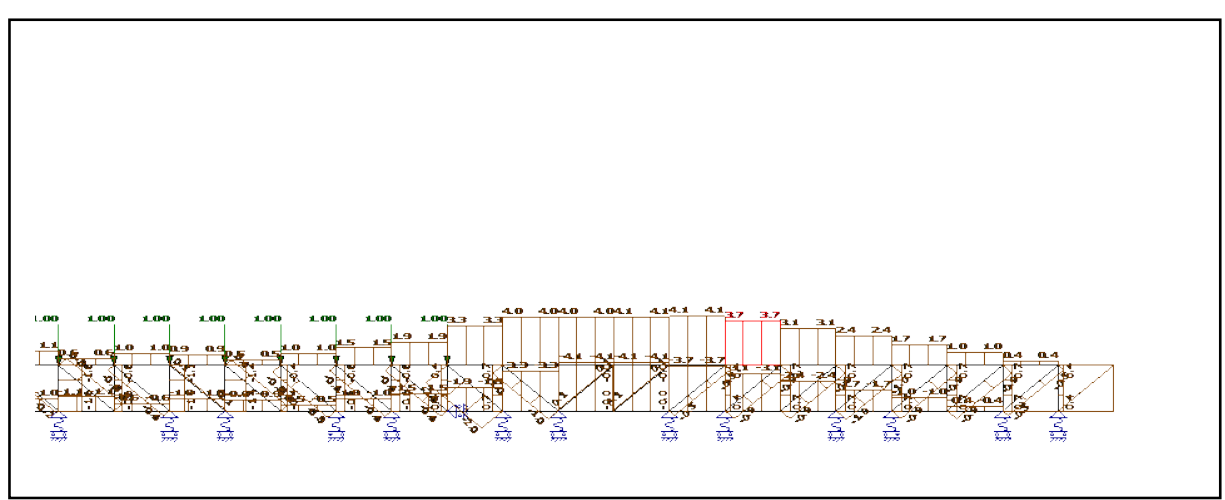

Figure 11: Asymmetrical load, forces.

Due to the permanent load the normal force is at maximum $0,6 \mathrm{kN}$, the stress is equal to $\sigma=2 \mathrm{MPa}$. Due to the symmetrical and asymmetrical load $\mathrm{q}=2,0 \mathrm{kN} / \mathrm{m}$ the normal force is at maximum respectively $2,9 \mathrm{kN}$ and $4,1 \mathrm{kN}$. Due to these forces the stress is respectively $\sigma=8 \mathrm{MPa}$ and $\sigma=11 \mathrm{MPa}$. The maximum stress due to the permanent and asymmetrical load is equal to $\sigma=2+11=13$ 
MPa. The deformation due to the permanent load and asymmetrical live load of $\mathrm{q}=2,0 \mathrm{kN} / \mathrm{m}$ is respectively $\mathrm{d}=0,15 \mathrm{~m}$ and $\mathrm{d}=0,49 \mathrm{~m}$.

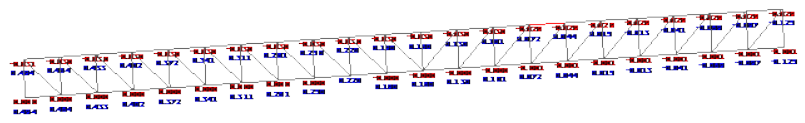

Figure 12: $\quad$ Asymmetrical live load, deformations.

In use the bridge can be supported at the riverbanks. Then the pontoons can be considered as flexible supports. Due to the upward forces acting at the pontoons the deformations and stresses acting on the trusses are decreased.

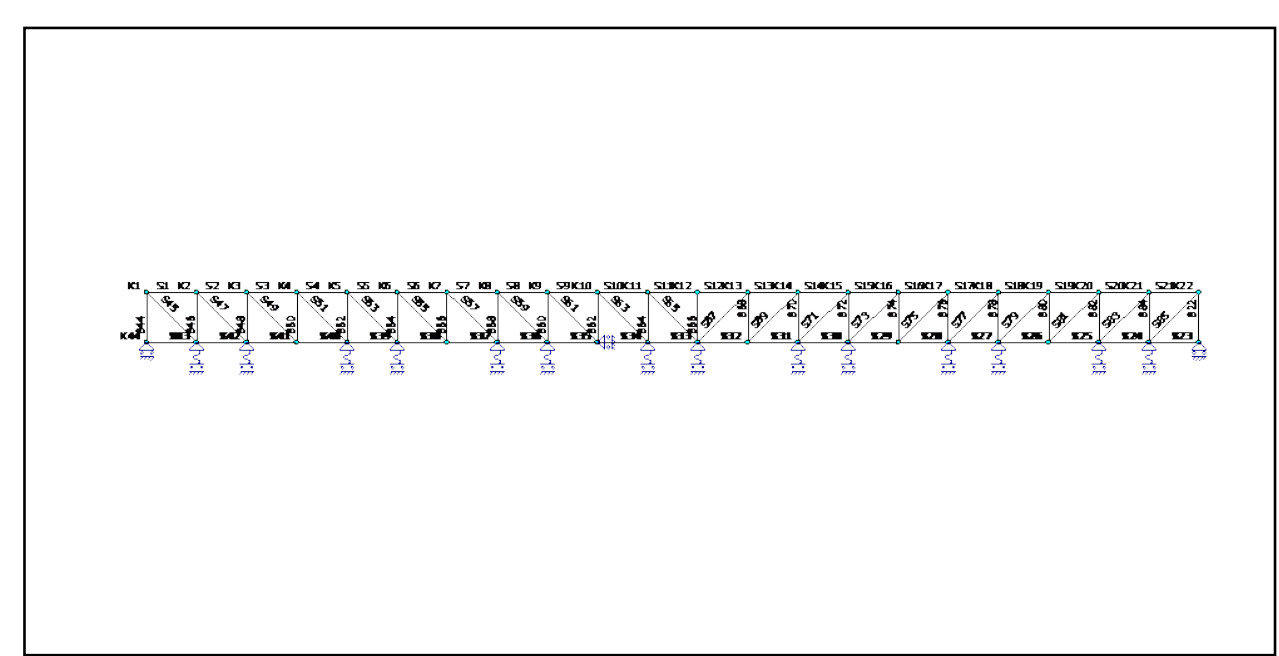

Figure 13: $\quad$ Trussed bridge in use, supported at the banks

The bridge is subjected to the permanent load, a symmetrically live load and an asymmetrically live load, $\mathrm{q}=2,0 \mathrm{kN} / \mathrm{m}$. Due to the permanent, symmetrically and asymmetrically live load the maximum normal load acting on the chords is respectively $15,4 \mathrm{kN}, 38,3 \mathrm{kN}$ and $20,6 \mathrm{kN}$. Due to these forces the stress is respectively $\sigma=40 \mathrm{MPA}, \sigma=100 \mathrm{MPa}$, and $\sigma=54 \mathrm{MPa}$. The maximum stress is smaller than the ultimate stress: $\sigma=140<250 \mathrm{MPa}$. 


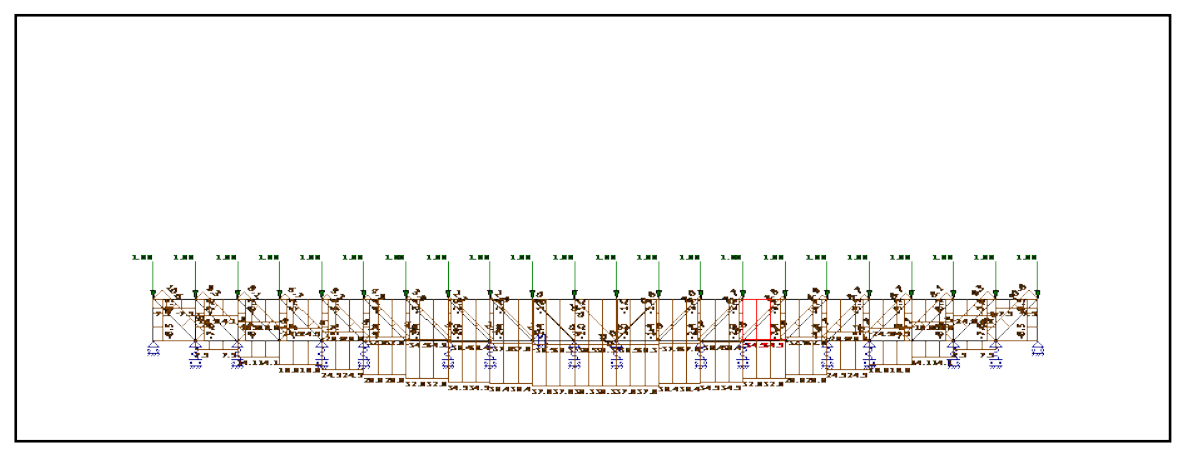

Figure 14: Symmetrical live load, forces.

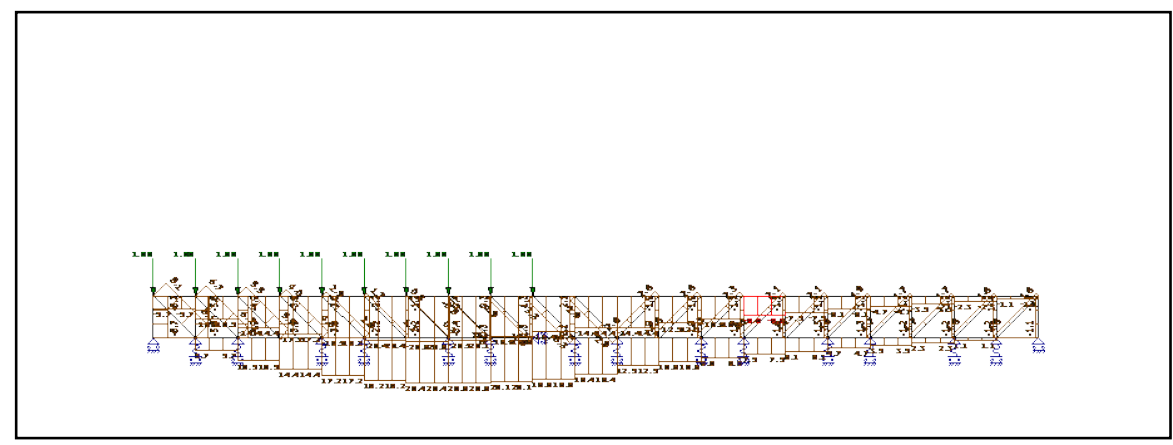

Figure 15: Asymmetrical live load, forces.

Due to the supports at the banks the deformations of the bridge are much smaller than for the bridge supported by the pontoons only. The maximum deformation halfway the span due to the permanent and live load is $0,06+0,14=0,2 \mathrm{~m}$. Thus if the bridge is supported at river banks the deformations decrease but the stresses acting in the chords of the trusses increase.

The handrail is subjected to a horizontal load of $1,0 \mathrm{kN}$ at maximum. Due to this load the strut is subjected to a bending moment $\mathrm{M}=1,0 \mathrm{kNm}$, for this bending moment the stress is equal to $\sigma=\mathrm{M} / \mathrm{W}=1,0 * 10^{6} / 5908=169<250 \mathrm{MPa}$.

\section{Conclusions}

The floating bridge is designed to resist several symmetrical and asymmetrical loads during construction and in the final state. In the phase of the construction the stresses in the trusses are pretty small but the deformations are quite substantial. In use if the riverbanks can support the bridge, then the trusses will 
span from bank to bank. For this stage the pontoons can be considered as flexible supports. Now the deformations will be smaller then during the construction, nevertheless the stresses acting into the trusses will increase. For the bridge as shown the maximal span is $21 \mathrm{~m}$. If the bridge is supported by pontoons only then stresses are pretty small, so the span of this bridge can be increased. However for a long floating bridge, not supported at the banks, it will be important to secure the bridge with ropes attached to stiff points at the river banks, to prevent the bridge of floating down the river, especially in case the current is strong.

Further research is needed to optimise and detail the design. It is advisable to make a mock up of the structure to test the design and improve the assembling of the modules.

\section{References}

[1] Timoshenko S. \& Young D.H. Technische Mechanica, Het Spectrum, Utrecht-Antwerpen, pp. 215-216, 1967.

[2] Timoshenko S. \& Woinowsky-Krieger S., Theory of Plates and Shells, McGraw Hill, Kogakusha ltd, Tokyo, pp. 214-216, 1959. 